\title{
Burnout Syndrome among Medical Workers at Kenyatta National Hospital (KNH), Nairobi, Kenya
} \author{
Louise Mapleh Kpoto ${ }^{7}$ \\ ${ }^{1}$ Consultant Psychiatrist, Machakos Hospital, Kenya \\ ${ }^{2}$ Lecturer, Department of Psychiatry, College of Health Sciences, University of Nairobi, Kenya \\ ${ }^{3}$ Senior Lecturer, Department of Psychiatry, College of Health Sciences, University of Nairobi, Kenya \\ ${ }^{4}$ Professor of Psychiatry, Department of Psychiatry, College of Health Sciences, University of Nairobi, Kenya \\ 5 Resident, Department of Counselling Psychology, School of Human \& Social Sciences, Daystar University, Kenya \\ ${ }^{6}$ Resident, Department of Health Systems Management, Kenya Methodist University, Kenya \\ ${ }^{7}$ Resident, Department of Obstetrics \& Gynaecology, College of Health Sciences, University of Nairobi, Kenya
}

Donald A Kokonya ${ }^{1 *}$, John M Mburu ${ }^{2}$, Dammas M Kathuku ${ }^{3}$, Ndetei DM ${ }^{4}$, Adam H. Adam ${ }^{5}$, Desire A. Nshimirimana ${ }^{6}$, Phocas S. Biraboneye ${ }^{7}$ and

*Corresponding author: Donald A Kokonya, Consultant Psychiatrist, Machakos Hospital, Kenya; E-mail:dkokonya@yahoo.com

Received date: April 3, 2014, Accepted date: September1, 2014, Published date: September 10, 2014

Copyright: (C) 2014 Kokonya DA, et al. This is an open-access article distributed under the terms of the Creative Commons Attribution License, which permits unrestricted use, distribution and reproduction in any medium, provided the original author and source are credited.

\begin{abstract}
Background: Little has been documented on the extent of the impact of work environment, interpersonal relationships, coping mechanisms and the burnout syndrome on medical workers in Kenya. Worldwide, medical workers have been found to be vulnerable to burnout syndrome, which in turn lowers the quality of their lives and health services provision.
\end{abstract}

Objective: To establish the prevalence rate of and factors associated with burnout syndrome among medical workers at the Kenyatta National Hospital, Nairobi.

Setting: Kenyatta National Hospital, Nairobi.

Design: Descriptive cross-sectional.

Subjects: Three hundred and forty five (345) medical practitioners and nurses with six or more months of work experience at Kenyatta National Hospital, Nairobi, Kenya.

Outcome measures: Prevalence rate, socio-demographic characteristics, factors associated with and influencing burnout syndrome among the medical workers at the Kenyatta National Hospital, Nairobi.

Methods: Proportionate allocation and simple random sampling strategy were used to recruit medical practitioners and nurses on the basis of qualifications, departments and distribution.

Results: The crude prevalence rate of burnout syndrome was $95.4 \%$. All sociodemographic factors and work environment related factors were found to be strongly contributing to their burnout syndrome. The burnout syndrome for socio-demographic factors were in excess of 95.0 and 'self-factors' contributed $14.0 \%$. Patients and their relatives contributed $40.5 \%$ while work environment contributed the largest proportion $(55.5 \%)$ of the total scores for burnout intensity.

Conclusion: Burnout syndrome was found to be high among medical workers at $\mathrm{KNH}$, Nairobi. The prevalence rate $(95.4 \%)$ in this study was higher than that found in studies in other countries worldwide $(66.0 \%)$. The major contributors to burnout intensity scores were work environment (56.0\%), patients' relatives $(41.0 \%)$ and self factors $(14.0 \%)$.

\section{Introduction}

Hardly, is there published work on burnout syndrome in Kenya to date, a condition that had not been classified by the ICD-10 or DSMIV TR 2000. Burnout was first described by Maslach in 1976 and the Maslach Burnout Inventory (MBI) first used as a research instrument in 1982 [1-6]. This is a recent development and it partly explains the scanty information about the syndrome among medical workers in Kenya. In the absence of published local scientific information, the ability to diagnose burnout syndrome has been limited.
Events in which health workers all over Kenya had been agitating for better terms of service followed by their exodus to other countries including South Africa, could suggest a possibility of their dissatisfaction at work whose underlying cause may be burnout syndrome. Studies on burnout syndrome among medical workers mainly in Europe and the United States of America have demonstrated that all cadres of health personnel suffer from various levels of burnout syndrome $[1,2]$. Burnout syndrome, or cumulative stress, is defined as a state of physical, emotional, and mental exhaustion caused by depletion of one's ability to cope with one's environment, resultant 
from one's responses to the on-going demand characteristics (stress) of the medical workers' daily lives [3].

High levels of cumulative stress in the lives of caregivers negatively affect their resiliency; making them more susceptible to burnout syndrome.

Among the medical workers, the "Silencing Response" [4, 5] occurs when they become unable to attend to the stories and experiences of their clients and patients but, instead, redirect to material that is less distressing for them.

According to Maslach \& Jackson [3, 6] burnout syndrome is a process characterized by low personal accomplishment, high emotional exhaustion and depersonalization resulting from cumulative effects of stress in a work-related environment and it strikes people in all walks of life and social standing, but those individuals who are in the helping professions are more vulnerable. It is characterized by progressive loss of energy, idealism and purpose [7] and it is likened to a slowly boiling pot which, if left covered for long, it may eventually spill over or a smoldering fire which if unattended to, it may spread beyond control [8]. The care giver responds by being alarmed, a stage in which the individual is no longer able to function at acceptable levels and relies on defense mechanisms to deal with stressors in order to maintain reputation. This is followed by the second stage, resistance, in which cynicism and rigidity are the main features. One is fixated on rules and regulations, very inflexible and becomes withdrawn and isolated from others.

This behavior might be missed out because the unpleasant attitude of the person involved might drive helpful colleagues away. If a person who used to join others for after work get-together, parties, and social events suddenly stops, that may be a sign that the individual is burning out. The final stage is referred to as exhaustion, in which a person might be lethargic and apathetic or very angry and cruel. This stage demands immediate attention. However, the action against him or her is usually disciplinary in nature and in extreme cases, termination of employment follows. Counseling from a professional who is trained in this area would be a better alternative [9].

The factors contributing to burnout syndrome among medical workers include time pressure due to work overload and critical decision making in emergency states. Others include service providerpatient dissonance when busy departments are overrun by patients, patient stress due to poor patient-practitioner bonding, poor professional relations due to territorial conflicts and disputes as well as cannibalism due to high expectations from young and inexperienced medical workers. In addition, technological advancement has exposed the care givers to increased contact through cell phones, social media, pagers and e-mails. Poorly functioning institutional systems characterised by shortage of staff, malfunctioning equipment and overtime wear out workers. This is abetted by the societal system that undervalues and under-appreciates medical workers. Medical workers are confronted with heart-breaking and frightening conditions that make them angry, frustrated, and hopeless. In despair, their frustrations are directed against all including patients [11-18].

American and Greek studies have shown that the young and productive medical workers were most vulnerable to burnout syndrome. It was found to have been precipitated by work environments in some cases and also in traumatic experiences as was the case in Israel. The Israel example was documented by Amnesty International in which medical workers were killed and others blindfolded and taken away [19-22, 29, 30, 31]. Women occupied unique position in society that made them more vulnerable to burnout syndrome than their male counterparts [23, 24]. A 1989 study in California, United States of America showed a relationship between marital status and burnout [25].

It has been known to affect medical workers with lower educational level and the less senior medical workers, but some vulnerable workers were also found to resist the effects of burnout syndrome due to their personality hardiness [26-28]. Burnout syndrome among medical workers has been found to present itself with lateness, defensiveness and working hard but achieving less.

Other presentations include lack of humor, easily frustrated, lack of empathy and compassion with co-workers and family members, conflicts at home and work, boredom and substance abuse. They are bitter, negative and hostile, experience body aches and show memory blocks among others $[11,12,26,27]$.

Two models have been proposed that influence the social support in the stress process related to the burnout syndrome. The direct effects model states that social support may help lessen the effects of the syndrome regardless of changes in stress levels. The second one, the buffering model, states that social support at work may result in the impact of stress on the subject or the evaluation that one makes of the stressors being lower. In the literature, there are buffering effects models with the relationship being significant only for workmate's social support in the second model. Studies have shown that the overall factors influencing burnout syndrome among medical workers are work environment related.

On the other hand, the workers strengths against burnout syndrome lay in the stability and control of the 'self factors namely, their personality hardiness, and support from supervisors and workmates, role stress variables (conflict and role ambiguity), personal accomplishment and self confidence $[10,32]$. This study attempted to establish the extent and impact of burnout on medical workers in Kenya and as it related to that found in other countries worldwide

\section{Methods}

This study was conducted over an eight week period from the last week of May to the first week of July. 2003 at outpatient clinics, theatres and wards at the Kenyatta National Hospital (KNH), Nairobi. The study site was the national referral hospital and the seat of the first school of medicine in Kenya, It was being manned by 2402 medical workers (1002 medical practitioners and 1400 nurses) in the year 2002.

The sample size required for the study was based on unknown estimated burnout prevalence of $50 \%$, a desired precision for the indicator of $5 \%$ and $95 \%$ confidence level. Fischer's formula for estimating the minimum sample size for prevalence in descriptive studies was used and applying a finite population correction factor (FPC) for total population of 2402, a minimum sample size of 332 was obtained and the study recruited 345 participants.

Proportionate allocation was used to determine the number of participants per department and the required participants selected using simple random sampling strategy. Seventy per cent $(70.0 \%)$ of the medical practitioners were employees of the University of Nairobi while $99.6 \%$ were nurses were employed by the $\mathrm{KNH}$. About $72.0 \%$ of the medical workers carried out bedside medicine and nursing, about $27.0 \%$ worked in theatres and $1.5 \%$ worked at the emergency/casualty department. The cut off duration of work at $\mathrm{KNH}$ for the inclusion criteria was 6 months. 
Citation: Kokonya DA, Mburu JM, Kathuku DM, Ndetei DM, Adam H. Adam, et al. (2014) Burnout Syndrome among Medical Workers at Kenyatta (KNH), Nairobi, Kenya. J Psychiatry 17: 1000142. doi:10.4172/2378-5756.1000142

Page 3 of 7

A standard Compassion Fatigue Self Test (CFST) whose alpha reliabilities ranged from 0.94 to 0.86 and a Tucker's Coefficient of Congruence of 0.91 was used to measure the levels of burnout syndrome in each of the medical workers.

The CFST measures both burnout syndrome and compassion fatigue but they are scored separately.

The administration of the questionnaire was done by an experienced mental health professional. The data was analyzed using the Statistical Package for Social Sciences (SPSS) version 10.0. Comparisons between those with and without burnout was carried out using Students $\mathrm{T}$ test for normally distributed continuous variables and Man-Whitney $U$ test for skewed continuous variables. For categorical variables, Chi Square and where applicable, Fisher's exact probability test was used. The level of statistical significance was held at $\alpha<0.05$.

\section{Results}

A total of 345 medical workers were recruited from 67 work stations at $\mathrm{KNH}$, of whom $62 / 345(18.0 \%)$ were medical practitioners while the nurses accounted for 283/345 (82.0\%). There were $94 / 345$ (27.2\%) male medical workers of whom $47 / 94$ (50.0\%) were medical practitioners and the other $47 / 94(50.0 \%)$ were nurses. The female medical workers constituted $249 / 345$ (72.2\%) of whom 15/249 (6.0\%) were medical practitioners and 234/249 (94.0\%) were nurses. The participants' age range was $23-53$ years with the youngest ( 23 years) and oldest (53 years) being nurses.

The mean age was 35.0 years (sd 7.6) and the median age of 33 years. Of the total population of medical workers, the medical practitioners constituted 62/1002 (6.2\%) while the nurses accounted for $283 / 1400$ (20.2\%) (Table1).

\begin{tabular}{|c|c|c|c|c|}
\hline & & $\mathbf{n}$ & $\%$ & Validity \\
\hline \multirow[t]{3}{*}{1} & Sex & & & \\
\hline & Male & 94 & 96.8 & \multirow[t]{2}{*}{$p=0.57$} \\
\hline & Female & 251 & 94.8 & \\
\hline \multirow[t]{6}{*}{2} & Age & & & \\
\hline & $<30$ & 97 & 97.9 & \multirow[t]{5}{*}{$x^{2}$ Not valid } \\
\hline & $31-35$ & 60 & 95.0 & \\
\hline & $36-40$ & 45 & 97.8 & \\
\hline & $41-45$ & 39 & 97.4 & \\
\hline & $>45$ & 32 & 96.9 & \\
\hline \multirow[t]{3}{*}{3} & Marital status & & & \\
\hline & Ever married & 274 & 94.5 & \multirow[t]{2}{*}{$p=0.21$} \\
\hline & Single & 70 & 98.6 & \\
\hline \multirow[t]{4}{*}{4} & Religion & & & \\
\hline & Catholics & 99 & 94.9 & \multirow[t]{3}{*}{$x^{2}$ not valid } \\
\hline & Protestants & 229 & 95.6 & \\
\hline & Muslims & 7 & 100 & \\
\hline
\end{tabular}

Table 1: Socio-demographic factors $(\mathrm{N}=345)$

The term $\mathrm{x}^{2}$ not valid in Table 1 is where conditions for use of Chi Square are not met.

\section{Prevalence rates}

Based on the Compassion Fatigue Self Test (CFST) scale for burnout syndrome, this study considered moderate burnout syndrome as the reference point. High and extremely high burnout syndrome were considered pathological, with a crude prevalence rate of 329/345 (95.4\%) among the medical workers at $\mathrm{KNH}$. The prevalence rates of burnout syndrome among medical practitioners were 60/62 (96.7\%) while that for nurses was $269 / 286(94.1 \%$ ) respectively (Table 1 ). 


\section{Sex}

Both male 91/94 (96.8\%) and female 238/251 (94.8\%) medical workers experienced high levels of burnout syndrome, though it was slightly lower among the females compared to males. The majority of the subjects in this study were females (72.8\%). The differences in the levels of burnout syndrome by gender did not have statistical significance $(\mathrm{p}=0.57)$ (Table 1$)$.

\section{Age}

All the medical workers of all ages experienced high burnout syndrome levels ranging from $95.0-97.9 \%$ ( $\mathrm{x}^{2}$ not valid). The majority of the workers were young, aged below 35 years (57.5\%) while $26.0 \%$ of the medical workers were aged above 40 years. The highest level of burnout syndrome $(97.0 \%)$ was found in the age group below 30 years while the lowest level of burnout syndrome $(95.0 \%)$ was found in the age group 31-35 years. The differences in the levels of burnout syndrome among different age groups were statistically insignificant ( $\mathrm{x}^{2}$ not valid) (Table 1$)$.

\section{Marital status}

The majority $274 / 344$ (79.4\%) of the medical workers were married compared to the single ones at $71 / 344(20.6 \%)$. All the medical workers suffered from high levels of burnout syndrome, though the single experienced slightly higher levels than the married though this was statistically insignificant ( $\mathrm{p}=0.21$ ) (Table 1).

\section{Religion}

The medical workers at $\mathrm{KNH}$ were predominantly Christian $328 / 345$ (95.1\%) making their comparison with other religions of no statistical value ( $x^{2}$ not valid). Catholics accounted for $94.5 \%$ while the Protestants accounted for $95.6 \%$ of the Christian subjects. They were only $7 / 345$ (2.0\%) Muslims in the study whose burnout syndrome level was $100.0 \%$ and members of other religious groups $8 / 345(2.3 \%)$ registered the lowest level of burnout syndrome (87.5\%) (Table 1).

\section{Profession}

The majority $283 / 345(82.0 \%)$ of the medical workers in this study were nurses compared to the doctors $62 / 345$ (18.0\%). The combined population of nurses and doctors suffered high and equal levels of burnout syndrome (96.0\%).The nursed suffered slightly lower level of burnout syndrome (95.1\%) compared to the medical practitioners (96.8\%). The differences in the levels of burnout syndrome among the medical professionals was not statistically significant $(\mathrm{p}=0.75)$ (Table $1)$.

\section{Education}

All the medical workers of different academic levels experienced high levels of burnout syndrome. The majority 273/345 (79.1\%) of the medical workers in this study, had pursued education up to college level while $72 / 345(20.9 \%)$ attained University education. There was a narrow range $(2.9 \%)$ of burnout syndrome among the academic groups. The level of burnout syndrome among those who attained college level of education (94.3\%) most of whom were nurses was just below that of the University graduates (97.2\%) most of whom were medical practitioners, a difference that was not statistically significant ( $x^{2}$ not valid) (Table 1$)$.

\section{Years as a practitioner}

The majority of the medical workers $235 / 345$ (68.1\%) had been in employment for up to 15 years and they experienced burnout syndrome levels in the range of $92.1-100 \%$. The practice duration bracket of $0-5$ years had the highest risk for burnout syndrome $(100.0 \%)$ followed by the $11-15(97.9 \%)$ and the $16-20(97.1 \%)$ duration of practice brackets. The lowest risk for burnout syndrome was found in the duration of practice bracket of 21-25 years (88.6\%). The range of burnout syndrome among the medical workers' duration of practice was small (1.1\%). The small difference in the levels of burnout syndrome rendered statistical significant invalid ( $x^{2}$ not valid) (table 1).

\section{Duration at KNH}

The largest number of the medical workers 231/345 (67.0\%) had worked for up to 15 years at $\mathrm{KNH}$ with a peak duration in the bracket $0-5$ year $(38.6 \%)$. The years of practice did not have any difference on the burnout syndrome with all the workers. Due to the high levels of burnout syndrome among the various categories of duration of work at $\mathrm{KNH}$, the difference on the burnout syndrome levels was smal (16.7\%) and did not have statistical significance ( $x^{2}$ not valid). However, a trend emerged in which working for more than 20 years $(100.0 \%)$ a risk factor for burnout syndrome was followed by working for less than 6 years $(99.2 \%)$ (Table1).

\section{Employer}

The majority of the medical workers 300/345 (87.0\%) were employees of KNH followed by the Ministry of Health (6.7\%). All the employees suffered high levels of burnout syndrome (83.3-100.0\%). The $\mathrm{MOH}$ employees had the highest levels of burnout syndrome (100.0\%) followed by those employed by the KNH (95.0\%). There were few employees of the University of Nairobi, self employed/others $(12 / 342)$ altogether. There was no statistical significance in the differences in the levels of burnout syndrome among the employers of the medical workers ( $\mathrm{x}^{2}$ not valid; $\mathrm{p}=0.70$ ).

The items used in burnout assessment were grouped into three clusters namely self. Patients and relatives and work environment. The contribution of each cluster to the intensity of burnout syndrome was assessed by computing the average percent (\%) of the total scores accounted for by the scores of each cluster. Factors pertaining to self contributed $14.0 \%$ while patients and their relatives contributed $40.5 \%$ of the burnout intensity scores among the medical workers at $\mathrm{KNH}$.

The workers' environment was the leading contributing factor (55.5\%) to the burnout intensity scores among the medical workers. The inherent self factors among nurses (23.6\%) had a higher risk for burnout syndrome compared to the doctors (7.0\%). On the other hand, patients and their relatives were at a higher risk for burnout syndrome among the medical practitioners (26.2\%) than nurses (14.4) while the work environment affected the medical practitioners (52.9\%) more than nurses (41.2\%).

\section{Discussion}

The results of this study support earlier findings in other parts of the world in confirming the existence of burnout syndrome among medical workers in this study, the prevalence rate of burnout syndrome among the Kenyatta Hospital medical workers was found to be even higher (95.4\%) than those found in other parts of the world 
such as the British Columbia (55.0\%), Austria (58.0\%) and North England $(66.0 \%) 16,17,18,12,19,29,32$. The youngest medical worker was 23 years old while the oldest was 53 years old. Most of the medical workers (59.0\%), mainly nurses were aged below 40 years, a finding similar the one done in Greece between 1986 and 1991 [1921].
This implied that the turnover rate of the old and experienced medical workers is high and the hospital is predominantly managed by young and less experienced medical workers.

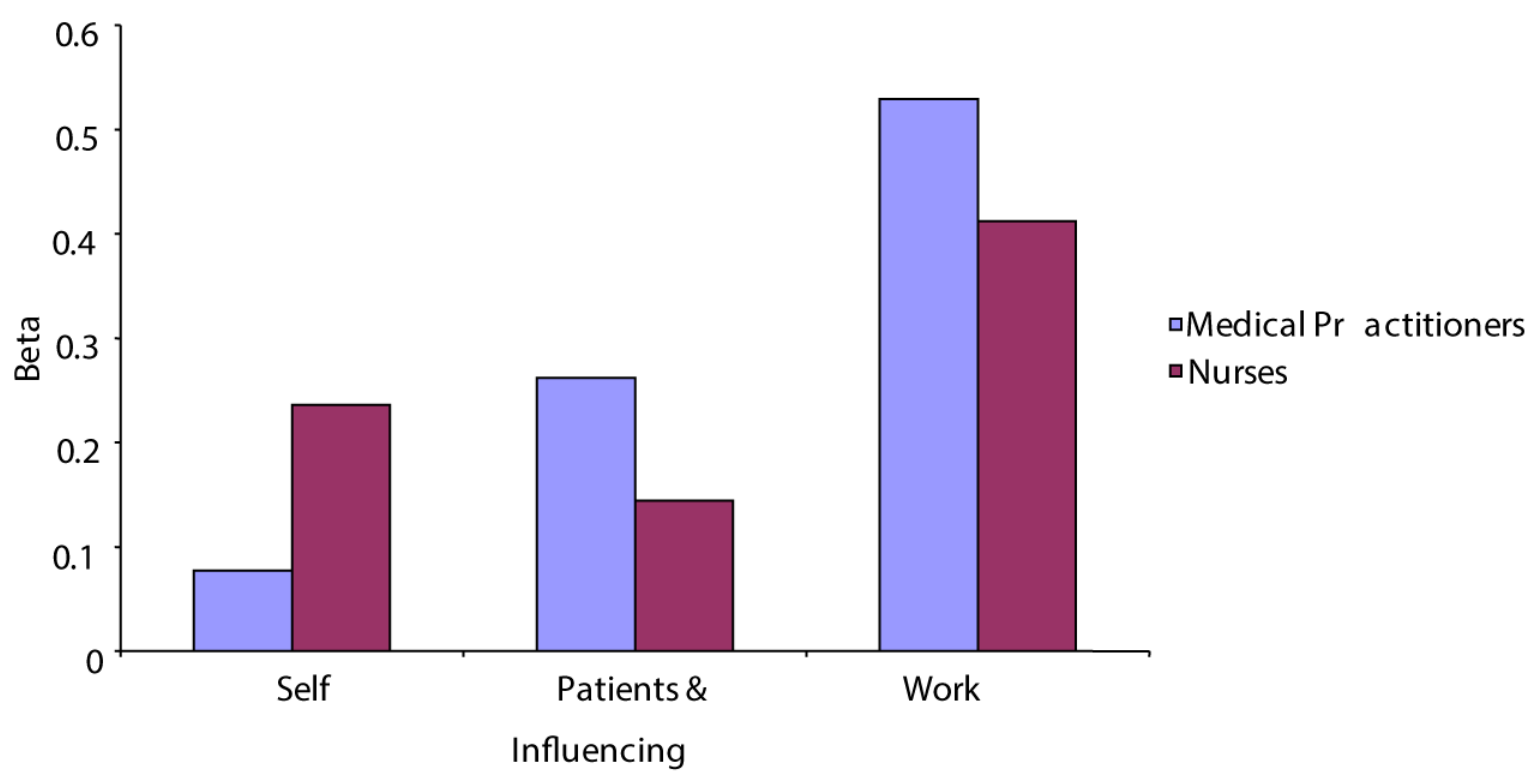

Figure 1: Regression Analysis by Profession and Influencing Factors

It further confirmed that the young and inexperienced medical workers were more vulnerable to burnout syndrome than the old, experienced and specialized medical workers.

These findings were similar to those found among 582 surgeons in America in which younger surgeons were found to be more susceptible to burnout syndrome $(\mathrm{r}=0.28, \mathrm{p}<0.01)$ and a strong relationship was noted between burnout syndrome and the desire to retire from employment early $(\mathrm{r}=0.50, \mathrm{p}<0.01)$. These findings among two distant and different groups of the same profession confirmed that burnout syndrome was an important problem for actively practicing medical workers which reduced their productivity during the time of their practice [22]. Both male (96.8\%) and female (94.9\%) workers were found to be experiencing high burnout syndrome levels.

This was different from the findings among American general and specialist physicians who were assessed for risk factors and prevention of mid-career burnout syndrome in the year 1997 in which females, due to their unique gender-linked stressors, were $60.0 \%$ at risk of burnout syndrome than their male counterparts23, 24. Whereas the Kenyan medical workers were predominantly married (79.4\%), both the single and married workers experienced high levels of burnout syndrome ( $98.6 \%$ and $94.5 \%$ respectively), a finding that was different from that among 79 University and College ombudsmen in 1989 in California, United States of America, among whom the marriage was protective against burnout syndrome [25]. Christians constituted $95.6 \%$ of the medical workers whose dominance produced burnout syndrome level of $95.1 \%$, implying that burnout was unresponsive to a caregiver's religious faith and needed more than one's faith to be overcome.
The same argument held for the differences in educational levels among the medical workers and their employers, the leading of whom was KNH $(87.0 \%)[26,27,28]$. Though not statistically significant for the duration of practice and work duration at $\mathrm{KNH}$, the majority of the medical workers $(78.0 \%$ medical practitioners and $89.0 \%$ nurses respectively) did not go beyond 25 years of active practice. Assuming that the medical workers in Kenya graduated at the age of about 26 years, this dropout rate could not be explained in terms of retirement age which stands at 55 years, but could justifiably be attributed to the tendency of the victims of burnout syndrome to have short half-life at work and their increasing desire to retire early due to the impact of burnout's strong feeling of lack of or reduced self fulfillment at work $(\mathrm{r}=0.50, \mathrm{p}<0.01)[22]$.

Given that the medical workers in Kenya suffer from extremely high burnout syndrome compared to their colleagues in other countries yet they still perform their duties without serious consequences as happened in the United Kingdom between the years 1990 and 1992 during which time 152 nurses, midwives and other healthcare providers killed themselves, taking the top spot among female suicides and was attributed to undiagnosed burnout syndrome [12].

The explanation to justify Kenyan medical workers resilience to catastrophic consequences lies in their 'personality hardiness 'as demonstrated in the Connecticut study in the United states of America in the year 2001. This study lent credence to the Kenyan medical workers' resilience through the theory of personality hardiness coupled with some degree of better professional leadership, co- 
operative work relationship, training and team supervision all of which were found to prevent burnout syndrome [12, 26, 27].

The inherent self factors among nurses $(23.6 \%)$ had a higher risk for burnout syndrome compared to the doctors (7.0\%). On the other hand, patients and their relatives were at a higher risk for burnout syndrome among the medical practitioners (26.2\%) than nurses (14.4) while the work environment affected the medical practitioners $(52.9 \%)$ more than nurses (41.2\%). Studies in Greece in the year 2002 showed that busy work environments such as emergency and intensive care units predisposed the medical workers to high burnout syndrome levels. ( $p=<0.032)[19,20,21,29]$. Such busy work environments were also closely related to the development of cardiovascular diseases as confirmed by empirical, theoretical and biological studies in Philadelphia in the United States of America in the year 200030. The environmental factors were followed by factors related to the relatives of the patients who also constituted part of the medical workers' environment and most of whom exacerbated the medical workers' burnout syndrome.

Some cases involve violence against medical workers either verbally or physically rendering the workers insecure. Physical and psychological traumas among medical workers were documented in Israel by Amnesty International in which medical workers were killed and others blindfolded and taken away31. Similar events have also happened in Kenya but only documented in the popular press, though there is now a need for scientific research on the subject of the security of the Kenyan medical workers.

The overall factors that were found out in this study were within the medical workers' environment or related to the environment while on the other hand, the workers strengths lay in the stability and control of the 'self' factors namely, their personality hardiness, and support from supervisors and workmates, role stress variables (conflict and role ambiguity), personal accomplishment and self confidence [32]. This study did not delve into the risks and mitigating factors of burnout syndrome. Being the first of its kind in Kenya, the study was therefore, more relevant for prevalence rates and sociodemographic factors correlates of the burnout syndrome among the Kenyan medical workers.

In conclusion, this study determined the prevalence rates of burnout syndrome and disaggregation of burnout syndrome by sociodemographic factors and profession. It also proved that the Kenyan medical workers as care-givers were no exception to the debilitating effects of burnout syndrome. The nursing career and middle college level of education were found to be risk factors. The sources of burnout syndrome were inherent self factors, parents and their relatives and their work environments in addition to sociodemographic factors. It therefore, means that the medical workers were progressively becoming less capable of coping with their work both in private and public lives, a future outcome of which could have serious repercussions to health services provision in Kenya. A strong recommendation for such a study is now justified on a larger scale. In the meantime, there is a need for a rescue programme for the Kenyan medical workers. The question that could be justifiably asked would be 'for how long would the medical workers in Kenya stand the test of time with such high levels of burnout syndrome, and is there any mechanism in place that monitors the impact of burnout syndrome on their outputs as a safety valve in their practice?'

\section{Acknowledgements}

To the participants(medical workers at $\mathrm{KNH}$ ), my co-authors, Professor C.R Figley, staff at Mathari and Kenyatta National Hospitals, the Ministry of Health, Republic of Kenya, teaching staff at the Department of Psychiatry, University of Nairobi and my family.

\section{References}

1. Erasmus L, Poggenpoel M, Gmeiner A (1998) [Burnout among psychiatric nurses in a private, psychiatric hospital 21: 9-16.

2. Amstutz MC, Neuenschwander M, Modestin J (2001) [Burnout in psychiatric physicians. Results of an empirical study]. Psychiatr Prax 28: 163-167.

3. MaslachC, Jackson SE (1982). Burnout syndrome in health professions: A social psychological analysis. In G.S. Sanders \& J. Suls (Eds.), Social Psychology of health and illness (3rd Ed., pp.227-251). Hillsdale, NJ: Lawrence Erlbaum.

4. Baranowsky AB (In Press) (1997) The Silencing Response in Clinical Practice. On the road to dialogue. In C.R. Figley (Ed.), Compassion Fatigue: Volume II. New York: Brunner/Mazel. Thirteenth Annual International Society For traumatic Stress studies Conference, Queen Elizabeth Hotel, Montreal, QB, CAN, November 9, 1997.

5. Danielli $\mathrm{Y}(1994)$ Psychotherapists' participation in the conspiracy of silence against the Holocaust. Psychoanalytic Psychology 1: 23-42. Thirteenth Annual International Society For traumatic Stress studies Conference, Queen Elizabeth Hotel, Montreal, QB, CAN, November 9, 1997.

6. Maslach C, Jackson SE (1981) The measurement of experienced burnout syndrome. Journal of Occupational Behavior 2: 99-113.

7. Moss VA (1989) Burnout. Symptoms, causes, prevention. AORN J 50: 1071-1072, 1074-6.

8. Cullen A (1995) Burnout. Why do we blame the nurse? Am J Nurs 95: 22-27.

9. Brake HT, Gorter R, Hoogstraten J, Eijkman M (2001) Burnout intervention among Dutch dentists: long-term effects. Eur J Oral Sci 109: 380-387.

10. Koeske, G.F, Koeske RD (1989). Construct validity of the Maslach Burnout syndrome Inventory: A critical review and re-conceptualisation. The Journal of Applied Behavioral Science, 25: 131-144.

11. Strickland D (1998) Balancing life's choices--all dressed up and too many places to go. AORN J 68: 634-636, 639-41.

12. Maunz S, Steyrer J (2001) [Burnout syndrome in nursing: etiology, complications, prevention]. Wien Klin Wochenschr 113: 296-300.

13. Phipps (1988) Stress among Medical practitioners and Nurses in the Emergency department of a General Hospital. Canadian Medical Association Journal, 139: 375-376.

14. Meissner JE (1999) Nurses. Are we still eating our young? 29: 42-44.

15. Schwab L (1996) Individual hardiness and staff satisfaction. Nurs Econ 14: $171-173$

16. Thommasen HV, Lavanchy M, Connelly I, Berkowitz J, Grzybowski S (2001) Mental health, job satisfaction, and intention to relocate. Opinions of physicians in rural British Columbia. CanFam Physician 47: 737-744.

17. Sullivan P, Buske L (1998) Results from CMA's huge 1998 physician survey point to a dispirited profession. CMAJ 159: 525-528.

18. Hayter M (1999) Burnout and AIDS care-related factors in HIV community clinical nurse specialists in the North of England. J Adv Nurs 29: 984-993.

19. Cantley BA (1991) The burnout syndrome among nurses in an acute care hospital. (Dissertation) Texas, University of Houston, 1991.

20. Bartz C, Maloney JP (1986) Burnout among intensive care nurses. Res Nurs Health 9: 147-153

21. Ceslowitz SB (1989) Burnout and coping strategies among hospital staff nurses. J Adv Nurs 14: 553-558. 
Citation: Kokonya DA, Mburu JM, Kathuku DM, Ndetei DM, Adam H. Adam, et al. (2014) Burnout Syndrome among Medical Workers at Kenyatta (KNH), Nairobi, Kenya. J Psychiatry 17: 1000142. doi:10.4172/2378-5756.1000142

Page 7 of 7

22. Campbell DA, Sonnad SS, Eckhauser FE, Campbell KK, Greenfiel DL (2001) Burnout Syndrome Among American Surgeons. . J Surgery (United States) Oct 2001 130: 96-702.

23. McMurray JE, Linzer M, Konrad TR, Douglas J, Shugerman R, et al. (2000) The work lives of women physicians results from the physician work life study. The SGIM Career Satisfaction Study Group. J Gen Intern Med 15: 372-380.

24. Gautam M (2001) Women in medicine: stresses and solutions. West J Med 174: 37-41.

25. Katherine MU (1989) Survey of Burnout level \& Stress Coping Techniques among University and College Ombudsmen. California Caucus of College and University Ombudsman, UCI Ombudsman: The Journal 1993

26. Kash KM, Holland JC, Breitbart W, Berenson S, Dougherty J, et al. (2000) Stress and burnout in oncology. Oncology (Williston Park) 14 1621-1633.

27. Cebrià J, Segura J, Corbella S, Sos P, Comas O, et al. (2001) [Personality traits and burnout in family doctors]. Aten Primaria 27: 459-468.
28. Taormina RJ, Law CM (2000) Approaches to preventing burnout: the effects of personal stress management and organizational socialization. J Nurs Manag 8: 89-99.

29. Adali E, Priami M (2002) Burnout among Nurses in Intensive Care Unit, Internal Medicine Wards and Emergency Departments in Greek Hospitals. ICUs and Nursing Journal. ISSUE 11th (July-September 2002) ISSN 1108-7366.

30. Belkic K, Schnall P, Landsbergis P, Baker D. The Workplace and Cardiovascular Health: Conclusions and Thoughts for a Future Agenda (1). Reproduced with the permission of Hanley \& Belfus, Inc., 210 South 13th Street, Philadelphia, PA, 19107.

31. Amnesty International Index: MDE 15/032/2002.Distr: PG/SG/CC Update on attacks on health personnel and disrupted health care Israel/ occupied territories.

32. Gil-Monte, P.R. and Peiro, J.M. (1997). A study on significant sources of the 'burnout syndrome' in workers at occupational centres for the mentally disabled. Psychology in Spain Vol 1 No1, 55-62. 